Revista Iberoamericana. Vol. LXVII, Núms. 194-195, Enero-Junio 2001, 219-238

\title{
EXCURSIÓN A VUELTABAJO DE CIRILO VILLAVERDE: VIAJE HACIA LA EMERGENCIA DE LA NACIÓN CUBANA
}

\author{
POR \\ EduARDo Guízar Álvarez \\ The University of Iowa
}

Uno de los propósitos fundamentales de Cirilo Villaverde en sus dos relatos de viaje de Excursión a Vueltabajo, publicados en El Album en 1838 y en el Faro Industrial en 1842, es conducir al lector a la búsqueda de una conexión imaginaria de pertenencia a partir de una serie de procedimientos discursivos y de técnicas narrativas que el autor emplea en su afán por inscribir nuevos significados fundacionales sobre la geografía cubana. ${ }^{1}$ Aquí estudio el segundo de los relatos, ${ }^{2}$ resaltando las técnicas textuales de Villaverde para insertar en el proyecto fundacional la heterogeneidad y cotidianidad de los seres, espacios y tiempos que ya habitan la isla de Cuba. Para alcanzar dicho objetivo, se hace necesario recorrer el territorio de manera tanto física cuanto literaria, para que, a partir del reconocimiento de la geografía cubana traducida en discurso literario, se vayan configurando una a una las diferencias dentro de un solo espacio nacional, que es la comunidad imaginada.

En su planteamiento sobre la comunidad imaginada, Benedict Anderson (53-57) propone el recorrido como una alegoría de un viaje en grupo, una especie de peregrinación secular de los habitantes de un espacio dado, quienes buscan llegar a un lugar determinado para forjar una comunidad. Los peregrinos son viajeros que se visualizan a sí mismos en un mismo plano horizontal y en un tiempo vacío. Discursivamente, la conciencia nacional se filtra por medio de un proceso de escritura y lectura, donde se entretejen los elementos auditivos, visuales, sensoriales y emotivos que buscan forjar la identidad nacional. La identificación entre los viajeros emerge durante el peregrinaje secular literario y geográfico, donde: "in experiencing them as travelling-companions, a consciousness of connectedness ('Why are we... here... together') emerges” (Anderson 56). La conciencia de un tiempo

\footnotetext{
${ }^{1}$ Roberto González Echevarría (100) explica que las culturas americanas han sido frecuentemente representadas en el género del relato de viaje, aludiendo así a una tradición discursiva que data de las Crónicas de la Conquista en el siglo xvi y a los constantes viajes de científicos europeos durante los siglos XVIII y XIX.

${ }^{2}$ El estudio presente converge con el escrito de Benítez Rojo en "Cirilo Villaverde, fundador” y una traducción del mismo en "Cirilo Villaverde, the Seeker of Origins". Benítez Rojo, a diferencia de este trabajo, utiliza como principal material de estudio el primer viaje de la Excursión a Vueltabajo de Cirilo Villaverde.
} 
vacío que emerge durante el peregrinaje en la Excursión a Vueltabajo no es casual, sino que forma parte de un proyecto de fundación nacional del Círculo de Domingo Del Monte. ${ }^{3}$

En 1820 y 1830 florece en Cuba el sentimiento antiesclavista e independentista dentro de los círculos literarios; atestan esta posición Félix Varela y José María Heredia quienes fueron obligados a abandonar la isla después del fracaso de la conspiración independentista y antiesclavista de José Antonio Aponte. Sin embargo, fueron dos los factores que, según cuenta Benítez Rojo (“¿Cómo narrar la nación?” 103) ayudaron a incrementar la censura y la represión ante las ideas abolicionistas e independentistas, que son el auge económico del que gozaban los productores de azúcar por un lado, y por el otro, el miedo a que Cuba, siguiendo el ejemplo de Haití, deviniera en una república negra. El discurso azucarero puede leerse en las "Reflexiones de un habanero sobre la independencia de esta isla” (1824) de Francisco Arango y Parreño, donde reitera lo expresado en 1816 sobre la imposibilidad de la Independencia, porque, según cuenta, un levantamiento traería como consecuencia una rebelión de los esclavos, la destrucción de los blancos, y la transformación de Cuba en otra Haití (Luis 60). La contraparte al discurso azucarero se encuentra en la Academia Cubana de Literatura, formada por un grupo de “criollos reformistas”, integrada por José Antonio Saco, Felipe Poey, Esteban Pichardo, José de la Luz y Caballero, y Domingo Del Monte, presentador cultural y crítico literario (Benítez Rojo, “¿Cómo narrar la nación?” 106), el cual fue acallado. Pero, a pesar del destierro de figuras como Saco, Domingo Del Monte continuó con la actividad literaria antiesclavista durante los años 1837 a 1844 con un grupo de jóvenes entre los cuales se encontraba Cirilo Villaverde. ${ }^{4}$ La narrativa nacional que comienza en 1837 en el seno del Círculo de Domingo Del Monte habría de durar hasta 1844, cuando sucede la Conspiración de la Escalera en la que, de acuerdo con las autoridades coloniales, los organizadores tenían en mente una rebelión general comenzando en la región de Matanzas, lugar al que Villaverde hace referencia en Excursión a Vueltabajo. Se incrementó entonces la represión a los intelectuales y el terror que se sembró por entre los esclavos, dando fin así al Círculo delmontino, con la consecuente tortura de Manzano, el fusilamiento de Gabriel de la Concepción Valdés (Plácido) el 22 de junio de 1844, junto con otros diez, el procesamiento de Luz y Caballero y el destierro de Del Monte en 1843(Benítez Rojo, “¿Cómo narrar la nación?” 105).

El relato de la segunda excursión a Vueltabajo busca cumplir una misión encomendada por el Grupo de Del Monte. El viaje, entonces, se traduce en una alegoría que busca llegar

\footnotetext{
${ }^{3}$ De hecho, el programa fundacional del Círculo de Domingo Del Monte acude a todos los géneros literarios posibles (Benítez Rojo, “Cirilo Villaverde, fundador” 771), publicadas en revistas como El Album, La Cartera Cubana, La Siempreviva, El Plantel, Revista Bimestre Cubana (Jensen 126-129). El proyecto de narrar la nación es la tarea de toda la vida de Villaverde a partir de 1837, dando inicio a este proyecto con su novela breve El espetón de oro (1838), y culminando desde el exilio con su novela Cecilia Valdés (1884), donde se retrata a lo largo del siglo xIx los propósitos fundacionales de la creación de una "narrativa antiesclavista" (Luis 1) a través de un estilo que Doris Sommer ha llamado "el romance nacional".

${ }^{4}$ Otros narradores son Félix Tanco y Bosmeniel, Pedro José Morillas, Ramón de Palma y Romay, José Antonio Echeverría, Anselmo Suárez y Romero, Gertrudis Gómez de Avellaneda y José Ramón de Betancourt. “Con excepción de los dos últimos, todos surgieron del Círculo de Del Monte” (Benítez Rojo 1994:106).
} 
a un centro. Para ello se inicia en el tren que sale de La Habana el día 20 de marzo de 1839, y la meca es San Diego de Nuñez, en la Vuelta Abajo, lugar de nacimiento de Cirilo Villaverde. Pero la meca en nuestro caso es también el punto de identificación nacional, máxime cuando es éste un viaje doble — tal como Villaverde mismo lo describe - en el que puede gozar de dos espacios, uno interior y otro exterior: las escenas de las vistas de los campos y las escenas de los pasajeros “de todas condiciones, colores y sexos” (Excursión 114). La heterogeneidad de sujetos que pueblan la nación es considerada un hecho fundacional ya consumado, donde no se intenta excluir a ninguno de sus habitantes, sino situarlos en el mismo plano de significación visto en el reconocimiento de la existencia en Cuba de pluralidad de culturas y heterogeneidad de seres y espacios físicos. Por lo mismo, la peregrinación, con Villaverde como guía, se inicia con la "caravana de hombres y mugeres en alegre compañía” (100), para dirigirse hacia Bahía Honda, pasando por el río a pie, "todos, sin escepción de sexos ni edades" (100), con un escenario que "no ofrece una sola vista, sino varias y diversas, difíciles de comprender en un solo país” (126).

Durante el viaje, pasan rápidamente por la vista del narrador escenas de "la variedad infinita de labranzas, árboles, fábricas y bellísimos paisajes” (116). La distancia entre los lugares se acorta cuando la velocidad aumenta, el tiempo se reduce y los espacios adquieren movimiento: "tal es la ilusión que se experimenta viajando en la mar y en los ferrocarriles, que nos parece que los objetos fijos se mueven, y nosotros nos estamos quedos” (116). La alusión alegórica al viaje como proceso de cambios hace referencia al restablecimiento de la historia en segmentos temporales. La memoria histórica puede reedificarse en la excursión con la presencia de "los primitivos moradores de Cuba" (8), entendiendo "primitivo" en su primera acepción de "antiguo, de los primeros tiempos de la historia" (Moliner II, 843). El relato reconstruye una primera fase de la historia de la nación, porque, aunque desaparecidos del plano físico, los grupos indígenas de la isla de Cuba no han sido borrados de la memoria colectiva, porque nombres como Tango farrango y el Pan de Guajaibón encarnan su presencia. Por lo tanto, para Villaverde, la historia de Cuba comienza a partir de una genealogía de raíces indígenas, cuya presencia discursiva marca la existencia de una naturaleza, figura del pasado y del presente. El pasado del espacio geográfico e histórico de la isla de Cuba da inicio con la población de "los indios cubanacanes, sabaneques, magones y guamuhayes” (179), entre otros que presenciaron la llegada de nuevos inmigrantes a la isla que después los desplazarían. La historia continúa en el siglo XvII, con el "horror que hacia las costas de la isla" (181) llevaban los piratas. El resultado fue el ver "inspirados a nuestros abuelos" (182) ante todas aquellas atrocidades cometidas por "los famosos filibusteros, de que son claro testimonio la traslación de PuertoPríncipe al Camagüey” (182).

Villaverde retoma en la naturaleza un nuevo espacio, un nuevo ciclo en su historia, porque, después del pasado indígena, "nada existe que revele que ha pasado una generación de hombres por esas tierras montañosas y aún vírgenes” (8). En la naturaleza de la geografía de Cuba, "nada de eso tiene nombre conocido" (8); por lo tanto, se vuelve necesario empezar a nombrar los espacios, ${ }^{5}$ y es por medio del viaje de re-conocimiento que Villaverde

\footnotetext{
${ }^{5}$ Así lo hace Villaverde precisamente cuando da un nuevo nombre a la meca de la peregrinación: "Nosotros por esto, y por estar el camino encajonado entre altos paredones de tierra, lo pusimos á aquel
} 
compone la nomenclatura, transformando el pasado histórico en ambos, tanto en espacio cubano como en un tiempo no sólo vacío, sino también histórico y discursivo.

Acompañan a Villaverde en el viaje el pintor y paisajista Sr. Alejandro Moreau, y el presbítero D. Francisco Ruiz, catedrático del Seminario de San Carlos, cada uno con propósitos diversos. Villaverde guía la peregrinación mientras la narra; Moreau, en cambio, muestra fines recreativos y científicos con el motivo de "recoger objetos de historia natural que remitir á Francia disponiéndose en tanto á admirar nuestra expléndida naturaleza" (113). Moreau representa de esta forma una mirada desde el exterior, marcada en la descripción que hace de éste el narrador: “Moreau que vestía levita verde abrochada...y sus cabellos rubios y bigotes retorcidos, al uso del siglo xviI, le daban aire militar, y extrangero además, que era el suyo” (146). Mientras tanto, el Sr. Ruiz, "hijo del propio suelo” (113), se une al viaje para "recibir nuevas sensaciones en medio de los frondosos bosques de la isla" (114), es decir, para buscar identificarse junto con Villaverde con la naturaleza cubana. El discurso narrativo en sí afirma ya los enclaves del sentimiento de comunidad desde el momento mismo en que se narra en tercera persona del plural: "nuestra gente campesina” (124), “nuestra misma ciudad” (125), y “el carácter de nuestra gente campesina” (130).

Uno de los momentos que conforman ya la historia de la nación se encuentra en la narración del ataque pirata a la isla, hecho histórico que Villaverde aprovecha para crear en la imaginación una unión entre las dos partes de la isla, el oriente y occidente, porque la tradición oral se ha encargado de crear una memoria colectiva:

\begin{abstract}
Aunque en la parte occidental no se tiene memoria de las rapacidades é incendios que se perpetraran en la oriental por aquellos hombres desalmados, la tradición y recuerdos de sus hechos atroces se han trasmitido y conservado tan al vivo cual lo publica la situación de Cabañas, San Diego de Nuñez, Bahía Honda, las Pozas, la Chorrera, Baja y Mantua...En aquellos tiempos de ignorancia suma, de despoblación y de horror, en que casi todos nuestros mejores puertos se hallaban sin un miserable castillejo, que vedara la entrada al enemigo común, nuestros abuelos no encontraron mejor defensa que las sierras; y entre sus asperezas asentaron sus hogares, que han venido a ser pueblos con el transcurso de los años: imitando el ejemplo de algunos pájaros, que no habiéndolos provisto Dios de garras, fabrican sus nidos en los huecos de las peñas, para preservarse así de los animales dañinos. (182)
\end{abstract}

Desde el momento en que existe un motivo de identificación entre los habitantes, esto es, la necesidad de protección y defensa, el cual, a su vez, explica la razón por la cual los pueblos cubanos fueron fundados en las montañas, se legitima la posesión del territorio con base en la constancia, la presencia física, y las experiencias, como el haber sufrido los ataques, que crean la memoria histórica. Asimismo, cuando Villaverde aprovecha para relatar la manera en que los pueblos se fundaron en lo alto de los montes como medio de defensa contra las amenazas del exterior, utiliza conscientemente la metáfora del veneno para relacionar los elementos que amenazan a la nación, con el fin de establecer un sentido de comunidad bajo la protección de la Naturaleza cubana misma, lugar donde simbólicamente

paso el nombre de: ‘Entrada a Vuelta Abajo,’ que á nuestro juicio es más significativo que el de la Yaya, con que le designan los naturales del país” (149). 
los animales ponzoñosos no existen. Cuba, por lo tanto, es un espacio donde las “alimañas y sabandijas venenosas, enemigas del hombre jamás se han guarecido en nuestros bosques” (12-13). Paradójicamente, esta visión de la naturaleza difiere en gran medida de la de Reinaldo Arenas, quien ve a la naturaleza cubana destruida: “A medida que el fulgor del bosque encantado avanza, nada, o casi nada de lo que acá nos rodea es ya real. Las flores, éstas que podemos tocar, no existen; los árboles, éstos bajo los cuales podemos pasearnos, no nos amparan" (Arenas, Necesidad 57). La mirada de Arenas presenta en su escritura los momentos en que encara, al tiempo que encarna, experiencias amargas en las que la naturaleza cubana sigue desapareciendo, porque los árboles y las flores han dejado de ser tangibles, y han dejado de servir de protección. Esta sensación de desprotección revela lo difícil que es para Arenas vivir la experiencia del exilio interno y externo, ${ }^{6}$ junto con otras experiencias difíciles en su vida. Casualmente, sin embargo, para Villaverde también ha desaparecido la naturaleza una vez que se encuentra dentro de los ingenios. La clara oposición entre Ingenios y Naturaleza queda marcada en la ausencia del verdor dentro del infierno, ese descenso ético al que los ingenios someten, empezando desde lo que él mismo había nombrado la Entrada a la Nación, o:

la Entrada a la Vuelta Abajo, perdió todo su encanto luego que descendimos de aquella altura, y tocamos, por decirlo así, la realidad. Sí, porque es mucha monotonía la de los campos interminables de caña, en que no hay un árbol donde guarecerse de los ardores del sol, ni variedad de verdura, ni de objetos, pues desmontados los terrenos, esos de la provincia primitiva del Mariel desde principio de este siglo han perdido completamente su frescura y virtud, y cuando no, las manchas de tierra esterilizada, cubiertas de exparto, las blanquizales y las cenagozas é inmundas cañadas, que les cruzan en todas direcciones, hacen fatigoso y triste el camino. (157)

Los obstáculos a los que se enfrenta Villaverde, como el mundo infernal de los ingenios, y a los cuales, logra escapar, crean esa narrativa literaria en la que, después de sobrevivir y lograr escapar del mundo infernal, el espacio de la naturaleza que lo protege se transforma en "campos de esmeraldas; y acá y acullá columnas de topacios sosteniendo la bóveda celeste, marco de este gran cuadro” (45). La metamorfosis de la Naturaleza en un cuadro fantástico, decorado por los colores y las formas de las piedras preciosas, añaden el valor estético que el lector va a compartir con el narrador, Cirilo Villaverde, en su capacidad de imaginar la nación. Su visión es la de mantener vivas esas primeras impresiones causadas la primera vez que se vive una experiencia: “Así no es de estrañar que yo, si veo los ingenios de azúcar al través del prisma de mis recuerdos históricos, me detenga á describirlos; pues creo verlos de muy diversa manera de como los ven los que mirándolos siempre ya no les impresionan” (161). Villaverde delata la imperiosa necesidad de cuestionar el mundo de los ingenios que desde niño conoció. Por lo tanto, si Villaverde resalta el mantener los recuerdos en la vida de los sujetos y las colectividades es porque "el

\footnotetext{
${ }^{6}$ Arenas vivió el exilio interno dentro de Cuba, la intolerancia por sus preferencias sexuales, las dosis de censura en sus escritos, y el rigor de la cárcel de la Cabaña y de la granja de rehabilitación. Después, al lograr salir de la isla por la vía del Mariel el 5 de mayo de 1980, vivió, como sucedió con Villaverde, la experiencia del exilio permanente.
} 
hombre vive de recuerdos" (9), y además, de la capacidad de imaginar: "Naturalmente aquella escena me trajo á la memoria las que yo había leido semejantes en los cuentos fantásticos de Hoffman, y me trasportó en espíritu á paises que no he visitado nunca” (365). La Historia y la Imaginación no podrían quedar compaginadas de mejor manera que al hacer referencia a las óperas y los relatos fantásticos y supernaturales del artesano del cuento gótico, el alemán Ernst Theodor Wilhelm Hoffmann (1776-1822), donde lo fantástico y lo supernatural se convierten en motivos estéticos que sirven a Villaverde para viajar por medio de la imaginación.

El viaje literario significa esa posibilidad del texto de transportarnos a espacios y tiempos nuevos para vivir la experiencia de la lectura y escritura, por medio de la capacidad de imaginar y vivir el mundo. Entonces la mirada narrativa se torna interior e interna a la vez. Es interior no sólo porque enuncia desde la subjetividad de Villaverde, sino porque recupera un presente y un futuro a partir de las experiencias pasadas del sujeto. Por otro lado, es interna en cuanto que se trata de una mirada de la geografía de la isla de Cuba de un viajero que vive en la misma, y que se distingue de aquéllos que provenían de Europa con motivos científicos. Esta mirada interna es precisamente la que hace uso del discurso romántico para representar una naturaleza personificada como Naturaleza, ${ }^{7}$ que sirve de origen, alimento y protección de la nación cubana, representada en la tierra, aquélla que proporciona la caña, el café y el tabaco, creando así la imagen armónica de una gran familia:

\begin{abstract}
De cuando en cuando alguna ceiba, la reina de nuestros bosques, que alzada sobre la llanura, estendida sus ramas á todas partes, en ademán de querer cubrir la tierra, como una madre á su hija querida, —atraía poderosamente nuestra atención, y en medio de las dudosas sombras de la madrugada, la tomábamos por una montaña; callado imponente guardián que velaba el sueño de los moradores de aquellas comarcas. (139)
\end{abstract}

La representación de la naturaleza como elemento femenino de fecundidad queda plasmado en la representación materna de la ceiba, que se convierte así en madre de la nación. La metáfora maternal es complementada con la figura paterna de la montaña para establecer la alegoría familiar como nuevo espacio nacional, donde la cabeza que gobierna a la isla es la ceiba reina.

La Naturaleza convertida en el primer espacio nacional por antonomasia, requiere de un pasado, que es construido a partir de la edificación discursiva y textual de las construcciones arquitectónicas por medio de la idealización y los códigos románticos que la decoran con piedras preciosas, de una belleza equiparable únicamente con las grandes construcciones arquitectónicas de la Grecia o la Roma de la Antigüedad, como por ejemplo en: “una caverna, cuyo arco en la boca, más grandioso y magnífico no le erijió el pueblo romano en honor de sus emperadores" (283). Las ruinas del pasado cubano, huellas de cubanidad, se rescatan en el texto, porque ellas delatan el pasado cultural: “[s]u aspecto era el de un templo griego, en forma de rotunda, arruinado...nichos que al parecer habían sido ocupados por estátuas en otro tiempo; rosetones de que habían prendido lámparas y otros adornos propios de los templos gentilicios y cristianos” (345). Los edificios contienen ese

\footnotetext{
${ }^{7}$ Retomo aquí la mayúscula que usa Benítez-Rojo (“Cirilo Villaverde, Fundador”) para explicar la
} manera en que Villaverde describe románticamente a la naturaleza, transformándola así en Naturaleza. 
elemento sagrado que infunde tanto respeto como admiración, en cuyas columnas de un blanco intenso se refleja la estética creada por el pasado arquitéctonico de la nación: “[l]a casa principal...obra magnífica de arte, parecía un templo griego...hallábase al fin de una larga guarda-raya del palmas, que semejaban columnas dóricas de blanquísimo mármol” (363). Ni siquiera la arquitectura medieval europea alcanzaría las dimensiones del detalle de los edificios de la Naturaleza de Cuba, tal como describe Villaverde el momento en que se presenta ante sí el Guajaybón, edificación protegida por una muralla de piedra, obra de la Naturaleza, pero que es "como si hubiera sido tallada por la mano del hombre, y luego sigue una superconstrucción de picos que ni más agudas ni más airosas ostentan sus agujas las catedrales góticas” (287). Estos tres picos del Guajaibón desde la distancia parecen uno solo, picos que asemejan la forma de un lomo de camello (287). Otros estilos arquitectónicos también pueblan el espacio nacional, y sirven de vestigios de encuentros pasados entre pueblos, como sucede con la referencia a la influencia de la cultura árabe en las culturas hispánicas, cuando el narrador describe los portales en San Diego de Nuñez, cuya “construcción participa más del estilo árabe que del gótico, que sin duda ofrece mayor resistencia; pero en sus adornos interiores, ejecutados por la sabia naturaleza...De las manos del hombre no ha salido obra tan acabada ni tan hermosa” (342). Esta representación de la Naturaleza, que difiere en gran medida de aquella del Sr. Poey, naturalista que también pertenece al grupo delmontino, ${ }^{8}$ quien ha escrito la historia del país en trabajos de materia geográfica, es testigo de que en Villaverde el motivo literario se anticipa al pragmático, desde el momento en que Villaverde reedifica discursivamente las ruinas de la Antigüedad Cubana con un código romántico, donde la Naturaleza, origen de la nación cubana, posee la sabiduría que la imaginación humana no alcanza a concebir. El uso de motivos literarios de Villaverde al equiparar la naturaleza a los estilos góticos, es utilizado también por Juan León Mera en su novela Cumandá (1879). ${ }^{9} \quad$ El asombro que producen los prodigios naturales es parte de la experiencia sublime de la mirada del narrador que logra el efecto de un ascenso estético y ético, en contraste con el descenso al mundo degradado de la esclavitud. Este rescate estético se logra por medio de las imágenes que el texto puede plasmar, concebidas y filtradas por la voz narrativa y autorial, por medio de la descripción de los colores y brillos, los sonidos y los aromas traducidos en obras de arte. Por eso, nada es común, sino que todo, tanto las sierras, las plantas, los árboles frutales, las montañas, los montes, como el mar y la tierra son tan bellos como espléndidos, y se guardan en la memoria de todo habitante de la isla. Lo mismo sucede con el sol: “Á corta distancia subimos una pequeña cuesta, desde cuya altura saludamos gozosos el sol de la Vuelta Abajo” (143). El sol no es un sol cualquiera; es el sol que pertenece a la región que es destino del viaje, y es el sol de los trópicos "que ya se suspendía en el horizonte y derramaba su pura y ardiente

\footnotetext{
${ }^{8}$ Precisamente Villaverde hace referencia a Poey, miembro del grupo delmontino, dentro del texto en relación con el acto de nombrar la geografía de Cuba: "nombres que merced á los interesantes trabajos geógraficos del Sr. Poey, ya se han registrado en las páginas de la historia de nuestro país, el año de 36, que fué cuando publicó su obra” (8-9), refiriéndose a Geografía de Cuba.

${ }^{9}$ Ver el capítulo de "Las selvas del oriente", donde Mera une un concepto romántico de la novela y una interpretación ideológica del país, por medio de unas analogías entre la naturaleza y las obras de arte en la escultura, arquitectura, pintura, música y poesía.
} 
lumbre sobre aquellos campos cubiertos aún con las nieblas de la mañana y sobre el apiñado caserío" (143).

El lector, junto con el narrador, se interna entre la naturaleza de San Diego de Núñez, una naturaleza, como hemos visto, sin malicia, una naturaleza, además, grandiosa y bella: "sembrada de ingenios y cafetales, teniendo por límites el mar azul y apacible; encima de todo esto, los moribundos rayos del sol, semejante a una sábana de gasa dorada” (45). Así, el espacio cubano se describe como una llanura inmensa cuyos límites están demarcados por el colorido del mar. En este caso, el discurso se vuelve insuficiente para representar la realidad que se extiende ante los ojos del narrador: "Bajando desplegóse ante nuestros admirados ojos un cuadro inmenso, maravilloso, que no hay lienzo que le contenga, ni mente humana que le conciba” (149-50).

El amor de Villaverde por Cuba va más allá de producir un efecto de identificación entre el peregrino y la Naturaleza. Esto es, Villaverde infunde un soplo de vida a la Naturaleza por medio del uso de la figura retórica de la personificación. Y entonces, una vez que ésta cobra vida, se regocija con la presencia de Villaverde personaje, para reconocerlo así, como heredero legítimo de Cuba:

entré en la población, radiante el rostro de alegría, regocijado el corazón y pareciendo que saltaban de gozo...la colina, el valle, el mismo río, el tronco de la palma, la mata de ciruelas, sitios y árboles que me vieron niño, inocente, juguetón, y hoy me ven con la cabeza cargada, el alma en contínua lucha con sus pasiones. (46, énfasis propio)

Los saltos de gozo de la naturaleza reconocen en Villaverde la legitimidad de la nación, "signifying the people as an a priori historical presence, a pedagogical object" (Bhabha 29899), tal como lo harán los patriarcas, como don Tiburcio, quien se inunda de alegría durante su encuentro con Villaverde: "los niños como los viejos no saben ni pueden ocultar sus alegrías ó sus pesares” (110).

A pesar de la belleza inigualable de la Naturaleza, dice Villaverde, la nación cubana no puede concebirse sin la presencia humana y la vida en comunidad: "Me es duro convenir con los filósofos que opinan que el mejor estado del hombre es el de la naturaleza; para mí esta idea es honrosa; yo no puedo concebir al hombre sino entre los hombres" (96). El siguiente paso entonces, es poblar la nación. Pero, antes de hacerlo, existe en Villaverde la preocupación de crear leyes que rijan los títulos de propiedad en la región de donde proviene el tabaco, el café y algún ganado. Su preocupación sobre la producción estará íntimamente ligada al relato en el que se introduce a los pobladores de Cuba, representados en los encuentros del narrador con los guajiros, los negros esclavos, sirvientes, los guías, los patriarcas, y los negros cimarrones. Todos y cada uno van a crear una conciencia nacional, entre ellos, la familia de los guajiros, quienes dan albergue y alimentos al narrador, y quienes a su vez representan el personaje paradigmático de la nación al ser trabajadores y hospitalarios. La identificación nacional se traduce entonces en el deseo de integración cultural y en una imagen de nación como una gran familia cuyo centro, como ya ha notado Benítez-Rojo (“Cirilo Villaverde, Fundador” 774), es la Casa Grande que clavó el patriarca “en señal de legítima propiedad sobre aquellas tierras” (66). La inmigración no se sugiere, aunque tampoco se niega como posibilidad de poblar la nación, sino que los personajes ya 
se encuentran presentes en la nación. La fundación y el funcionamiento de lo cubano desde la perspectiva de Villaverde y del grupo delmontino debe emerger a partir del acto de poblar de manera apropiada el espacio cubano. Así, la nación se configura en primer lugar a partir de las relaciones presentes entre los sujetos que (con)viven en ella. La nación hecha pueblo tuvo la fortuna de nacer "en la más hermosa casa de cedros”, donde ya existen las tradiciones con una genealogía que legitima lo que ya es propio, un espacio físico que ya les pertenece a la "larga familia de sus pobladores" (62), para quienes “todo esto que poseemos lo hubimos de nuestro padre, y por lo tanto nos pertenece exclusivamente con título legítimo” (63). Posteriormente, la "tribu de Jacob, comenzó a derramarse por las sierras, formando varias familias” (63), cuando empezó a fundarse la testamentaría por medio de la cual repartieron y dividieron las haciendas.

Villaverde se coloca como narrador-viajero-personaje-eslabón ${ }^{10}$ que va a conectar el pasado con el presente y a su vez el futuro de la nación. Es también el eje que une a los personajes y a los espacios rurales y urbanos en uno solo. Benítez-Rojo ha apuntado que "escribir de lo cubano, pues, es escribir de la búsqueda de lo cubano; revisitar una y otra vez los distintos caminos que conducen a su centro imposible" ("Cirilo Villaverde, Fundador" 776). Las revisitas durante la peregrinación son actos de autoconocimiento como colectividad, como cuando el narrador hiperboliza la visita hasta convertirla en un gran acontecimiento para los pobladores de la región: "la visita que se hace un vecino a otro, todo se solemniza como una fiesta” (100), donde la música y los bailes populares son el patrimonio que conforma "las costumbres y el carácter más marcado de los pueblos" (101). El espacio de la Cuba naciente busca legitimarse en aquellos elementos propiamente representativos del espacio cultural, geográfico, temporal, e imaginario, y comienza a acumular por medio del discurso una memoria que conforma una cultura que pertenece a la isla de Cuba como espacio nacional, donde: “(t)he scraps, patches, and rags of daily life must be repeatedly turned into the signs of a national culture” (Bhabha 297). El relato costumbrista hace que dichos elementos sean reconocidos como parte del espacio nacional emergente, y que encuentren un nuevo cauce de significación que los convierta en auténticos símbolos de cubanidad, tal como sucede con el personaje del campesino cubano, quien construye su casa y sus muebles en la manera en la que se construye a sí mismo como sujeto con un carácter y costumbres cubanas ya bien delineadas: "Otro escritor célebre ha dicho que el estilo es todo hombre, y yo acomodando esta bella frase á mi antojo, soy de parecer que la casa del guajiro es todo él” (102). La imagen con que el narrador construye al campesino cubano es la de un ser económico, laborioso y honrado, que se expresa en el buen trabajo de sus muebles y en la limpieza de su hogar. El hecho de que las casas se estén edificando sobre bases bien firmes es de suma importancia para Villaverde, porque ello se traduce en significados fundacionales en los que los sujetos han pasado de un estado nómada a otro sedentario para establecerse como pueblo. En caso contrario, existe el riesgo de retroceder,

\footnotetext{
${ }^{10}$ El término de "personaje eslabón” proviene de Miguel Barnet, el cual identifica al personaje que mantiene la conexión con la memoria colectiva del país. Es de esta manera que Cirilo Villaverde se coloca como eslabón que conecta el pasado con el presente y el futuro de Cuba. Nos dice Barnet que: "El superobjetivo del gestor de la novela-testimonio es más funcional, más práctico. Debe servir como eslabón de una larga cadena en la tradición de su país. Debe contribuir a articular la memoria colectiva, el nosotros y no el yo" (294).
} 
“porque está muy propenso á caer en el estado nómades, el hombre, el pueblo, que no alza su vivienda sobre bases firmes, y no cultiva una propiedad” (102).

La familia Paroli, compuesta por los padres con dos hijos casados, funciona como paradigma de la sociedad campesina cubana. Su tierra está sembrada de granos y legumbres para la subsistencia familiar. También, se cultiva el tabaco para su gusto diario. La cera proveniente de las treinta colmenas sirve una doble función, que es, por un lado para alumbrarse, pero por el otro, para "esportar a la ciudad" (103), con lo que se sugiere una economía nacional que ligue a la ciudad con el campo. El viaje de Villaverde, unas veces a caballo, otras a pie, algunas otras veces en tren, se convierte en un testimonio que diferencia los ingenios de azúcar de los otros tipos de cultivo, como el tabaco y el cacao. A pesar de ser La Habana el centro comercial e intelectual de la isla, sus asociaciones con la Cuba Grande de la industria azucarera y sede del gobierno colonial llevan a Villaverde a resistir este posicionamiento nacional, y a proponer un centro cubano sentimental que se relaciona con la Cuba Chica de producción no azucarera, situada en "San Diego de Núñez, pueblecito de las montañas, donde he tenido la suerte de nacer y pasar los primeros años de mi juventud...desde cualquiera altura de sus cercanías presenta un golpe de vista mágico y nuevo” (185-186). El Camino Real conecta la región de la Vuelta Abajo, el espacio del interior de la isla donde se produce el café y el tabaco, desde donde se alcanzan a ver los ingenios de azúcar y la cría de ganado, con el espacio de la ciudad, La Habana. Villaverde, quien ha habitado ambos espacios nacionales, los describe como silencioso y bullicioso respectivamente. En el interior, se cría todo tipo de aves, se ceban cerdos, se construyen arados, y no conforme con eso, el resto de la familia teje "muy finos sombreros de paja" (103).

Continúa Villaverde con la representación paradigmática de una economía nacional vista en la familia de los Paroli: “Los dos hijos, á la constitución física, sana y fuerte, de hombres que nacieron para el sudor y para el polvo, juntaban el amor al trabajo, que el padre les había trasmitido desde tierna edad con su ejemplo; a tal que nunca se ha hecho uso de esclavos para cultivar la tierra” (104). La narrativa de Villaverde exhorta a la resistencia del uso de las manos esclavizadas para trabajar la tierra. En su lugar, solicita hacer uso de las manos y la tierra propias para producir los alimentos para el consumo familiar y para la exportación. El trabajo con ética, llamada por Villaverde el amor al trabajo, se sitúa en oposición al uso de esclavos, que el autor considera innecesario y sobre todo, inmoral. La falta de una ética hacia el otro que ha sido racializado y sometido a las relaciones de trabajo por medio de la dominación es para Villaverde el motivo más fuerte que intenta atacar desde diferentes posiciones, como ésta en la que alaba el trabajo del campesino cubano mientras marca una oposición binaria entre el amor al trabajo y el trabajo obligado mediante el sistema esclavista.

Villaverde pone gran énfasis en su discurso para motivar a los demás viajerosperegrinos de la isla a seguir el ejemplo de los Paroli, enfocándose principalmente en el padre: “¡Al verlo tan afanoso, solícito y vivaz, no pude menos que esclamar entre mí: - He aquí el agricultor de la isla de Cuba! ¡He aquí el labriego de los países verdaderamente industriosos!” (104). El discurso de resistencia al uso de esclavos para la producción del azúcar es parte del programa del grupo delmontino, donde el trabajo, mas no la esclavitud, es la base para forjar la nación cubana, y es así que Villaverde relata que la función científica 
de las teorías económicas no es necesaria para que el sujeto actúe con ética: "Este hombre rústico, como por adivinación ha puesto en práctica el principio económico de los publicistas, de que la riqueza está fundada en el amor al trabajo, sin haberlo aprendido en los libros. ¡Cuántos otros hubieran seguido su noble ejemplo...!” (104). Paroli es ya parte constitutiva del pueblo cubano, puesto que ha habitado la Vuelta Abajo por más de treinta años, y su ética de trabajo es el esfuerzo laboral del sujeto mismo. La filosofía de Paroli sobre el trabajo apoya a Villaverde en su afán por generar los valores esenciales de la nación, donde la utilización de otras manos en relaciones esclavistas debe desaparecer: "la inconstancia y caprichos de los amos, hacía muy varia é inestable la suerte de los pobres sirvientes, aconteciendo además que el hombre acostumbrado á mandar esclavos, perdía el amor al trabajo, tornándose holgazán, decidioso, rudo” (105).

A pesar de que Paroli no tiene el título legal de posesión de la tierra, sus características paradigmáticas lo nombran poseedor “con título lejítimo” (106). Villaverde siente compasión y amor por aquel hombre que ha dejado años de trabajo en el espacio cubano. Por lo tanto, queda inscrito en la memoria colectiva de la nación como el agricultor paradigmático de Cuba. En una relación de reciprocidad, Paroli ha dado su vida a ese territorio cubano tal como la tierra cubana le ha servido y le ha proveído del alimento para subsistir: "Si en el espíritu hay resignación, el cuerpo donde se alberga ha perdido todas sus fuerzas y vá desmoronándose como una pared fuera de su aplano, y el espíritu queda apagado bajo las ruinas del cuerpo” (106). La corporeidad de Paroli se hace tierra, se desmorona para servir de emblema de resistencia a la esclavitud.

Benítez Rojo explica que en El guajiro de Villaverde se propone la cultura del campo como parte auténtica de la cultura nacional, donde entran a la novela cubana "la manera de hablar y las costumbres campesinas, las coplas improvisadas de la décima, el baile del zapateo, la pelea de gallos, y numerosos artefactos culturales que van desde la vivienda techada con hojas de palma (el bohío) hasta el machete, la hamaca, el taburete de cuero crudo y el sombrero de yarey” (Benítez Rojo, “¿Cómo narrar la nación?” 115). El guajiro, como el gaucho Martín Fierro, “canta décimas y gusta de los jolgorios, es ducho en las faenas del campo y en el uso del arma blanca, está desempleado y vaga a caballo, es orgulloso y temperamental, no es feliz en amores, mata a un hombre en un duelo, y finalmente, huye tierra adentro para escapar de la justicia” (Benítez Rojo, “¿Cómo narrar la nación?” 115). Las nociones de cubanidad quedan inscritas en el guajiro, donde Villaverde "legitima la cultura del campo proponiéndola como parte auténtica de la cultura nacional” (115).

El guajiro, nos cuenta Villaverde (82), al nacer, tiene acceso a tres oficios, que son los de la mayoralía, el del veguero, y el del sitiero. Villaverde se dedica a describir al guajiro sitiero, y prefiere no ahondar en las dos primeras posibilidades de empleo para el guajiro, y comienza haciendo una comparación con la manera en que el guajiro y el indígena construyen su casa. El guajiro es entonces el descendiente directo del pasado indígena, en el momento en que el guajiro se construye a sí mismo con los mismos elementos que lo hacía el indígena, puesto que el guajiro construye su casa en forma cuadrangular siguiendo el modelo de la casa indígena, con la única diferencia de que ésta última era circular en vez de cuadrangular (83). Pero, el problema que Villaverde nota en aquel guajiro sitiero que siembra únicamente para comer es que reduce su vida económica a la pobreza (86): "Ved aquí por qué en un país esencialmente agrícola, pocos, muy pocos son los que ejercen una 
verdadera agricultura” (86). Por otro lado, se encuentra el guajiro célibe, quien "en un fogoso caballo con el brillante machete, las espuelas de plata y el pañuelo de seda atado al cuello” (87), sigue algunas veces el camino fácil para convertirse en carretero, mayoral, maestro de azúcar, boyero, arriero, tratante de animales, jugador de gallos, etc. (86). Este estado nómada del guajiro sitiero que no construye un hogar propio no es recomendable para la construcción de la nación. En contraste, la familia de los Paroli no se reducía a la industria del sitiero, porque, además de cultivar diversos tipos de granos y legumbres para mantener a su familia, la esposa sexagenaria y sus dos hijos, ya hombres casados y a su abrigo, sembraban tabaco, tenían treinta colmenas, criaban de todas aves y cebaba cerdos, "entre tanto sus hijastras y su esposa tejían muy finos sombreros de paja” (193).

Villaverde habla de la falsa percepción viciada sobre el guajiro, según la cual, “á primera vista, no parece sino que el guajiro, hombre feroz y enemigo irreconciliable de toda la sociedad, siempre está en son de atacar y defenderse” (88). Sin embargo, esta visión es errónea, nos cuenta Villaverde: “Pero nó. En esto, como en otras muchas cosas, ciertamente que los guajiros se diferencian en gran manera de los gitanos y los beduinos. Por lo común son alegres, de mansa condición, dados al trabajo, generosos y amigos fieles, apasionados y entusiastas” (88). "Después de la moza, el caballo y el machete, no hay objeto, no hay diversión que llame tanto la atención del guajiro, como sus gallos y sus perros” (89). La vanidad y el amor propio son características esenciales del guajiro, explica Villaverde (98), tanto cuanto son hospitalarios, económicos, laboriosos y honrados (192). Por otro lado, la descripción de la joven guajira es la de mantenerse en un solo lugar: "tomase su casa por una cárcel estrecha, y se dirige pensativa” (96), esperando a su amado.

En oposición a la representación de Paroli está el hatero de los cafetales e ingenios de azúcar (el guajiro célibe): "Sus maneras y aspectos eran rudos, sí, pero no de hombre imbécil; antes al contrario, su reserva y su gravedad infundían respeto, y le asemejaban á uno de aquellos señores feudales de que nos hablan las crónicas del siglo Xv" (324). El discurso hibridizado de la situación feudal y las relaciones de trabajo en Cuba reiteran la resistencia a la vida de los ingenios por ser éstos indeseables para el proyecto delmontino de nación. Las relaciones entre los habitantes de Cuba deben estar basadas en una repartición equitativa de la tierra: "Mas ahora nosotros, alcanzando mejores tiempos, y mas civilizadores medios, que en vez de aumentar las poblaciones, les escatimemos el terreno para dividirle en grandes propiedades y erigir feudales castillos donde asentar el lujo y la holganza, —en Dios, y en mi ánima que no tenemos disculpa ni escusa” (136). la isla:

Los ingenios son prueba contundente de que la situación feudal se sigue repitiendo en

Porque estoy en la firme persuasión de que aquí se ha resucitado el feudalismo, si no en cuerpo y alma al menos en cuerpo. ¿Pues qué otra cosa son que castillos feudales tanto y tanto ingenio y cafetal como pueblan los campos de la isla? ¿Cada finca de esas no es una población aparte, donde se estilan muy diversas costumbres, donde particularmente les serfs de la gefe $e^{11}$ no tienen comunicación lícita con los de otras fincas, y donde, en fin,

\footnotetext{
${ }^{11}$ Probablemente, les serfs de la gefe se refiere a los siervos o esclavos que sirven a un amo o señor, por lo general atados a la tierra del señor y transferidos con ésta de un dueño a otro.
} 
cada amo es un señor de vasallos? Si faltan los caballeros armados de punta en blanco...y los torneos y los juicios de Dios, y los trovadores, y los príncipes protectores de las letras...pues poesía era matarse los campeones... (160-61)

Esta alegoría es la referencia más directa a la relación de los intelectuales del grupo delmontino con el poder económico y político de la isla. En este punto del peregrinaje, el viajero se encuentra en los ingenios de azúcar, el mundo de la esclavitud y de la producción azucarera mecanizada, de lo que Benítez Rojo llama la Plantación, un tiempo que se ubica en el espacio de la Cuba Grande, que delata el olor suave del guarapo que proviene de ahí: "Pero hoy, á la ganadería han sucedido las plantaciones de café, caña y tabaco, cuyo fruto se envía al mercado público” (246). El humo que ven en la distancia es un presagio de que la naturaleza de la isla está siendo desplazada por los ingenios de azúcar:

Al principio el ruido del hacha...y el humo de las tumbas de árboles incendiados, elevándose en densas columnas por sobre las lenguas de fuego, y los montes, nos daban á entender, que aquellas vírgenes tierras que caían á nuestra derecha, después de muchos años y siglos, iban á ser trasformadas en campos de caña, y de plátano, y de maíz, y de arroz...Pero...al ruido del hacha, y al humo de las quemazones, sucedieron el cantar melancólico de los pájaros... (256)

La tristeza del cantar de los pájaros proviene de Villaverde, convertido para entonces en naturaleza cubana. Su voz es la de los pájaros; su voz se convierte en Naturaleza, para poder ofrecer el testimonio del paso de la plantación a la Plantación, como ha descrito Benítez Rojo al crecimiento repentino de la producción azucarera, donde la destrucción de la naturaleza cubana era el primer signo de que sería desplazada por ingenios azucareros basados en el modelo esclavista. ${ }^{12}$

El viajero ingresa en el espacio temporal de la Edad Media para conocer los campos de caña y las fábricas de los Señores Herrera:

Luego descubrimos todos sus campos de caña, por estar en una llanada dilatadísima, en el centro de la que se elevaban las fábricas del ingenio, pequeño pueblo ó señorío de

\footnotetext{
${ }^{12}$ En su ya clásico estudio El ingenio, Moreno Fraginals describe la situación de la quema de los bosques en una sección que titula "La muerte del bosque” (I, 157-63). En un tono crítico, Moreno Fraginals relata la manera en que el azúcar arrasó los bosques. Ya a finales del siglo xviII, durante la expansión azucarera del gran boom de 1792-1802, cada año se derribaban 500 cab de bosque (6710 ha), para ser utilizado como leña en los ingenios, mientras otra gran parte del bosque era quemada para utilizar el terreno en la siembra de caña, hasta alcanzar en 1844 la cifra de 53,680 ha. En ese mismo año, continúa Moreno Fraginals con un tono irónico y crítico, "la junta encargada de la preservación de los bosques declaró que la legislación forestal había dado felices y satisfactorios resultados" (158, énfasis en el original). El proceso de quema de bosques comenzaba con "chapear el monte", donde los macheteros cortaban los bejucos y enredaderas que rodeaban a los troncos. Posteriormente, se procedía a realizar "la tumba", donde se derribaba los árboles centenarios. Se dejaba pasar de treinta a cuarenta días antes de proceder a "la quema”, con el fin de que la vegetación se secara. El desmonte podía llevarse a cabo “a tumba y deja” o “a tumba y limpia”. El primero de estos trabajos necesitaba de las manos de los esclavos para amontonar los troncos no consumidos por el fuego, mientras de que el segundo tipo de desmonte requería de la repetición de los fuegos y se trozaban los troncos para que se quemaran en su totalidad (157-63).
} 
nuestros tiempos, al cual no falta ni la torre de la casa de calderas, que en la época del feudalismo europeo se convirtió en señal y símbolo de dominación. (144)

El discurso híbrido es una alegoría de la situación de la isla: el uso de vocablos como señorío, torre, feudalismo y dominación en sincronía con el discurso de la naturaleza cubana representa lo ambivalente, contradictorio e incongruente de la (re)producción de los ingenios de azúcar. En el texto se representa como un regreso en el tiempo, que se traduce en un retroceso para el avance del proyecto nacional.

El discurso de Villaverde es una crítica al sistema con el que funcionan los ingenios azucareros y los cafetales. Tal como lo expresa William Luis (1), el círculo delmontino ofrece una visión compasiva hacia los esclavos y la esclavitud, en un momento en que la esclavitud está en su apogeo, y Cuba es el productor más importante de azúcar del mundo. Como en Cecilia Valdés (1882), la alegoría que usa Villaverde para introducirse en el mundo del trabajo del esclavo en el ingenio es el infierno, traspuesto a un espacio del mundo y descrito como un descenso ético:

ardían los candiles de la casa de calderas, porque eran tales y tan espesas las nubes de humo que se desprendían del jugo de la caña hirviendo y de las fornallas, que todo lo llenaban y oscurecían, dándole al sitio aquel, y a los trabajadores negros, desnudos de medio cuerpo arriba, el aspecto de un abreviado infierno. (146-47)

La idea del descenso moral como un infierno tiene ecos literarios en obras como la Divina Comedia (1306) de Dante Alighieri y en El paraíso perdido (1667) y El paraíso recobrado (1671) de John Milton, tal como Villaverde lo declara: "parecióme que se realizaba ante mis ojos el pasaje que refiere en Dante de la bajada al infierno, ó la caida de Lucifer que canta Milton” (119). De hecho, muchos de los elementos que aparecen en esta parte de la excursión son referencias intertextuales de la narración en Cecilia Valdés, como cuando Isabel Ilincheta descubre lo infernal de la situación esclavista. En Cecilia Valdés, al igual que en Excursión a Vueltabajo, el viaje por el ingenio continúa por el batey, donde se encuentran con "la enfermería, ó el hospital” y con escenas que de manera crítica describen lo terrible del degradado mundo de la esclavitud: "vimos varios negros estropeados, viejos la mayor parte, y todos muy flacos, que tomaban el sol sin duda á falta de lumbre con que sacudir el frio intenso de la mañana” (145). La alegoría de la situación infernal de los ingenios de azúcar hace de ésta una narración antiesclavista, porque para construir la nación se requiere abandonar la continuación de las relaciones esclavistas en los ingenios, y por lo mismo, se hace uso de técnicas narrativas que representan al mundo de la esclavitud como lo que es, un espacio oscuro, cerrado, cuyos habitantes están condenados al trabajo eterno, desarrollando así relaciones intertextuales con el discurso filosófico: "Todo esto forma una bulla y confusión de tal naturaleza, que no pueden comprenderse bien, sino comparándolas con las que nos dicen los teólogos reinan en esos lugares destinados por Dios á las almas condenadas" (147).

La alegoría hasta ahora puede resumirse así: la belleza de la isla cubana y las relaciones entre los habitantes de la isla de Cuba están siendo consumidas por el fuego, símbolo de la explotación, dentro de los castillos medievales, que representan a los ingenios azucareros, 
los cuales, a su vez, se convierten en un infierno. El problema se extiende cuando la metáfora atraviesa los niveles de una realidad, cuando el fuego escapa de ese nivel simbólico del infierno (el fuego infernal de las calderas y las relaciones de dominación dentro de los ingenios) para convertirse en un fuego que empieza a devorar la isla. Así, en Excursión a Vueltabajo, el fuego intenta desplazar a la Naturaleza Cubana, es decir, a Villaverde convertido ya en Naturaleza Cubana:

los dos fuegos se encontraron frente á frente por una ley de atracción, formando una bóveda
de llamas, que haciendo estallar las yerbas todavía verdes, como dos ejércitos en combate,
se resolvían en un humo espeso y sofocante. Pasar por en medio era forzoso: toda la sabana
estaba ardiendo: el fuego que había trazado un gran círculo, amenazaba encontrarse y
envolvernos, tal vez donde más pábulo tenía. (324-25)

Pero, alegóricamente, Villaverde no alcanza a ser consumido por el fuego, como tampoco Cuba es consumida por la esclavitud en el ingenio, que amenaza acabar con la isla. Este momento de incendio que devora a la Naturaleza cubana logra superarse, como un presagio y un deseo de Villaverde de resistir a las fuerzas infernales que intentan consumir la Naturaleza para convertirla en campos de caña de azúcar.

Después de que la Naturaleza ha sobrevivido al Holocausto, aparecen algunos personajes que no simbolizan relaciones de dominación de ningún tipo para llenar el espacio vacío de la nación: "un mulato fabricador de jaulas de pájaros y de cocuyos” (328), los monteros "blancos y rubios como dos alemanes" (339), tal como había sucedido con el “mozo negro, robusto y alto de cuerpo”, quien saludó al narrador al principio del relato diciendo: "bueno ría mi amo" (14), con la misma "risa apacible de que siempre lo vi bañado" (14). Las primeras figuras que pueblan la nación cubana de reciente creación, la Cuba que sobrevive al Holocausto, son seres con diferencias raciales, el mulato criollo, el blanco criollo, y el negro esclavo que se dirige a Villaverde con un "mi amo” y con un lenguaje característico del personaje cubano. Este personaje criollo blanco se contrasta con la figura del criollo blanco dueño del ingenio, desconstruyendo así los binomios de amo y esclavo racialmente. Se desconstruye también las relaciones fijas de trabajo basadas en las construcciones raciales de los personajes ya que todo tipo de personajes de diferentes construcciones raciales mantiene formas de trabajo fuera del ingenio, fuera de la Cuba Grande, devoradora e infernal. El espacio de la Naturaleza cubana se purifica y se redime en ese mismo fuego que destruyó a la isla. En cuanto al personaje negro, es necesario resaltar que es significativo el hecho de que se trata de un negro esclavo del "siñó Mratine Brabosa”, que tiene ya un color local dibujado en su forma de vestir y de hablar, con elementos culturales transculturados que forman parte de lo propiamente cubano.

El estado de ánimo del narrador cambia al encontrarse con este último personaje; pasa de: "los ojos del caminante se pierden con tristeza y con melancólico vagar” (10), a otro más alegre: "Su fisonomía examinada despacio era la más alegre que se ha visto” (14). Este cambio en el estado de ánimo del personaje, no es exclusivo a él, sino que refleja el estado de ánimo del narrador y de la Naturaleza Cubana misma. Benítez Rojo ("Cirilo Villaverde, Fundador” 771) afirma que este personaje, el mozo negro, que aparece en la primera parte, es una especie de personaje mágico, con una doble naturaleza hermética que es a la vez 
benéfica y maléfica. Esta naturaleza mágica predice ya los elementos mágicos que Carpentier asocia con el elemento negro e indígena en América en su introducción a El reino de este mundo. Así, la naturaleza mágica del esclavo negro es apoyada por la "aparición repentina” (16) en la taberna de San Salvador. Su presencia en el espacio nacional coincide con la de un "francés de nación” y con la de un guajiro (18). También, “contra toda regla común” el espacio nacional está poblado por “catalanes, castellanos y montañeses peninsulares” (18). Esta es la continuación de la alegoría de la manera en que Cuba está ya poblada por una heterogeneidad de sus habitantes. Estos personajes son el negro mágico, el francés que representa a los inmigrantes europeos que ya no son vistos como extranjeros extraños, sino como inmigrantes recientes, gente de nación, acompañados por los personajes de la península. Por último, aparece el guajiro. Este personaje, como hemos visto, es el paradigma de los rasgos cubanos porque su trabajo no ha estado basado en relaciones esclavistas. De esta manera, alegóricamente, el vacío con el que el narrador asociaba la melancolía comienza a desaparecer.

El guajiro es, por lo tanto, el emblema de la nación. Para Villaverde, el guajiro es lo que pudo significar para Sarmiento el gaucho de las pampas en Argentina. Villaverde se propone desmentir la imagen del guajiro que lo dibuja de la siguiente manera: "hombre feroz y enemigo irreconciliable de toda la sociedad, siempre está en son de atacar y defenderse” (89), y nos recuerda que esta visión está equivocada, porque el guajiro es, en realidad, muy trabajador, por lo que cae dentro de los valores positivos del proyecto de Villaverde para forjar la nación cubana.

El personaje de la mujer, a quien Villaverde describe como principio de civilización del que el hombre carece, aparece de forma tangencial como elemento necesario para el proceso de establecer la identidad nacional cubana. Nos dice el narrador-viajero:

Pero la mujer, según nuestra propia observación y la de escritores de concepto, no hay duda, que por sí sola, es el móvil de la sociedad, y un principio, ó como ahora se dice, un elemento de civilización. Ella que ha endulzado y reprimido siempre la ferocidad del hombre abandonado á sus instintos brutos...que le ha infundido el amor al trabajo, que lo ha reunido en sociedad. (393-394)

La exclusión del personaje femenino en la construcción del proyecto nacional, sea del texto o de los circulos literarios, es mencionada por Villaverde al reducir la participación del personaje femenino a ser el elemento de civilización y no de participación. A pesar de que es la mujer quien ha infundido el amor al trabajo en el hombre, primer valor ético del proyecto nacional de Villaverde, su participación en el proceso de establecer la identidad cubana queda reducida a una participación oblicua e indirecta, casi como si fuera una sombra del personaje masculino.

El texto de Villaverde Excursión a Vueltabajo presenta las construcciones paradigmáticas de la femineidad y masculinidad:

Es fama en toda esta parte occidental de la isla la amabilidad y la belleza de las mujeres de Guanajay: los hombres por lo contrario, no gozando de la una ni de la otra cualidad en grado superior, distínguense, sin embargo, por su afición á los buenos caballos, á las diversiones y al juego, en especial al de los gallos. (143) 
El personaje de la mujer se representa con ciertos valores superiores al hombre en la estética de su cuerpo y en su función cultural, pero se la margina de una posición de agencia como figura pública. Esta misma crítca la realiza Benítez Rojo al llamar "la matriz logocéntrica que da luz a los discursos nacionales” (“Cirilo Villaverde, Fundador” 771) al Círculo delmontino. Los límites de una construcción nacional patriarcal son transgredidos en los estudios que resaltan la participación en el proyecto nacional de autores como Gertrudis Gómez de Avellaneda y María de las Mercedes Santa Cruz y Montalvo, Condesa de Merlín, como por ejemplo el texto de Adriana Méndez Rodenas, Gender and Nationalism in Colonial Cuba, donde se contrasta el papel de la escritura de la Condesa de Merlín en su función paródica frente a la estética realista y las ideas positivistas del Círculo de Domingo Del Monte.

Una vez que han desfilado algunos de los personajes que van a construir la nación, se vuelve necesario pensar que dicha comunidad debe estar basada no sólo en el trabajo, sino además, en la educación formal: "Nuestras reflexiones, siguiendo viaje, rolaron sobre la suerte y estado de esos hombres de campo, sin instrucción de ninguna clase, a quienes los dueños de las fincas rurales confían sus más cuantiosos intereses” (149). Lo incongruente de un sistema que separa el crecimiento económico del educativo es criticado por la voz narrativa del relato: "nos parecen tan incompatibles los adelantos y riqueza comercial con el atraso moral é intelectual...que ya mas de una vez ha conturbado nuestro espíritu” (149). Villaverde hace la crítica más fuerte en esta cita donde no solamente lanza un ataque al atraso educativo de los esclavos sino también, a la vez, al moral y ético del sistema esclavista, a cambio del mero avance económico.

El camino de reflexión del ascenso y descenso ético se ve interrumpido por una serie de descansos durante el peregrinaje, cuando Villaverde se detiene para describir y dejar huella en la escritura y en la memoria de la nación tanto el nombre como las características físicas, el mapa, los servicios, las tiendas, la iglesia, la escuela y la cantidad de sujetos que habitan cada pequeña comunidad que van a pasar a formar parte de otra comunidad mayor, la comunidad imaginada, Cuba. Es ésta una manera de llevar a cabo un censo, un recuento de lo existente; un ejemplo es el pueblo con doble nombre Pilar o Vereda Nueva:

Calcúlansele al Pilar ó Vereda-Nueva, sobre 600 habitantes entre blancos, negros, libres y esclavos; casas 126, entre ellas 1 botica, 4 tiendas de víveres, 6 mistas, 2 de ropa, 1 herrería, 2 zapaterías, 2 barberías, 1 panadería, 4 tabaquerías, 1 carpintería, y 1 escuela de primeras letras, (que en el momento de escribir esto se halla vacante). Su iglesia [...] (136)

El hecho de saber y conocer quién habita el espacio y con lo que se cuenta hasta el momento es una manera de reconstruir la Historia de la nación, a partir de un pasado que ya existe y que se retoma en la escritura. Esta recopilación de datos sobre el pasado sirve también para poder visualizar por medio de un examen las necesidades presentes de la nación cubana. El hecho de cuantificar y clasificar lo que se tiene es también una manera de demarcar lo propio, lo propiamente cubano.

Villaverde utiliza la misma metáfora que Martí para describir a la comunidad como sujeto. En su ensayo “Nuestra América”, Martí llama “sietemesinos” a una América que no está en su plenitud de maduración, una nación que todavía está por nacer. La alegoría de 
la comunidad como sujeto en Villaverde se remite a alcanzar la madurez al convertirse Cuba en nación: "hasta que ya hombre hecho, esto es, pueblo” (62). Así, Cuba alcanza la madurez cuando es ya la comunidad imaginada.

El lector participa en el proceso de identificación con vistas a la emergencia de la nación, como dice Barnet: "El lector debe hallarse dentro de los libros como si fuera un personaje más, moviéndose, gesticulando, imaginando, escribiendo, enjuiciando” (290). Villaverde logra esta función cada vez que dialoga explícita e implícitamente con el lector: “...Admírese el lector...¿YY crece ese pasto, preguntará alguien, en una tierra árida...evaporada por el fuego? Crece, responderemos...Y esta es la prueba más notable que puede darse de la feracidad del suelo cubano” (314). La resistencia del suelo cubano es análoga a la resistencia del pueblo, resistencia que puede verse en el cuerpo del esclavo y en la imagen de la caña, ${ }^{13}$ otro símbolo de la nación cubana. El suelo cubano convertido ya en sujeto cubano refleja la entereza y fortaleza que es motivo de admiración frente a la situación de los ingenios de azúcar. Con relación a la producción azucarera, Villaverde visualiza a la isla de Cuba como el lugar donde la historia se repite:

El célebre S. B. Vico ha dicho en su historia de la humananidad [sic], que ella estaba condenada á una perpetúa rotación, al corso, ricorso, como los astros en su órbita. Esta hipótesis, que puede ser exagerada y aun falsa respecto de algunas naciones de Europa, respecto de nosotros me parece bastante exacta. (160)

Cuando Villaverde hace referencia a los Principios de una ciencia nueva relativa a la naturaleza común de las naciones (1725) del historiador y filósofo italiano Giovanni Battista Vico (1668-1744), ${ }^{14}$ que se conecta directamente con el título del libro La isla que se repite de Benítez Rojo, alude a la repetición del modelo de industria azucarera que se reproduce en cada isla del Caribe, pero también, una y otra vez a la repetición de este modelo productivo en la historia de Cuba. Este discurso que hace consciente la repetición en el tiempo tiene una doble función: por un lado, intentar romper con la vida cíclica de la producción azucarera de la isla, buscando sugerir otras formas de trabajo que no estén basadas en el ingenio azucarero, y por el otro, destacar la separación del nexo con Europa, no sólo por una conexión geográfica, sino cualquier otra conexión imaginaria, ya sea histórica o cultural de Cuba con Europa. Las comparaciones con otras regiones llevan a Villaverde a delimitar en el campo de lo simbólico y lo imaginario lo que es Cuba y lo cubano. Diferencia lo que es cubano de lo que no lo es. Cuba no es España, ni América del Norte ni del Sur, ni Arabia. Cuba es Cuba, con una geografía propia, con el pan de Matanzas, las Tetas del Managua y el Guajaibón. Los habitantes, el pueblo, la comunidad imaginada y el contacto humano son, relata Villaverde, la complementariedad a la belleza natural del territorio cubano.

${ }^{13}$ Ver Guízar Álvarez y Méndez Rodenas.

${ }^{14} \mathrm{Al}$ marcar una distinción de la historia cíclica de cada pueblo en tres edades, la edad divina, la edad heroica y la edad humana, Vico se apartó de las teorías cíclicas de la historia. Vico aseguraba que estos períodos no recurren exactamente de la misma forma, sino que están sujetos a las modificaciones que las nuevas circunstancias y los procesos históricos imponen; por lo que el historiador no puede ser asimismo profeta. 
El guía-narrador es quien conduce a la meca de identificación a los peregrinos: narrador, personajes, autor y/o lectora/lector. Todos hemos compartido un recorrido simultáneo de alegrías, tristezas, soledades, cansancios. En las últimas líneas de la narración, Villaverde se despide, y decide quedarse en la Vuelta Abajo, el lugar al que él pertenece y el lugar que le pertenece. Se despide de los viajeros, tanto de Moreau como de Ruiz, "triste y preocupado”, pero sabiendo que en el viaje hemos "visto en ese breve tiempo, cosas para nosotros ignoradas hasta entonces, y peregrinas” (367). El peregrinaje ha llegado a su fin; el objetivo se ha cumplido; todo viajero, lector o no lector, siente "al separarse una sensación de dolor y melancolía; porque sólo los corazones que gozan ó padecen juntos saben comprenderse y amarse" (367). El objetivo se ha cumplido. Los peregrinos han llegado al final del viaje, cuyos propósitos fundacionales han creado en la mente de los viajeros una conexión que les permite imaginarse a sí mismos en un mismo plano de identificación en el tiempo y en el espacio, al lado de Villaverde, escritor-narradorpersonaje-eslabón que se legitima a sí mismo como Cuba y lo cubano.

\section{BiBliografíA}

Anderson, Benedict. Imagined Communities. Reflections on the Origin and Spread of Nationalism. Londres/Nueva York: Verso, 1991.

Arenas, Reinaldo. Antes que anochezca. Autobiografía. Barcelona: Tusquets, 1992. Necesidad de Libertad. Mariel: testimonios de un intelectual disidente. San José: Kosmos, 1986.

Barnet, Miguel. "La Novela Testimonio. Socio-Literatura”. Testimonio y Literatura. René Jara y Hernán Vidal, eds. Minneapolis: Society for the Study of Contemporary Hispanic and Lusophone Revolutionary Literatures, 1986. 280-302.

Benítez Rojo, Antonio. “Cirilo Villaverde, fundador.” Revista Iberoamericana LVI/152153 (julio-diciembre 1990): 769-76.

"Cirilo Villaverde, the Seeker of Origins". Coded Encounters. Writing, Gender, and Ethnicity in Colonial Latin America. Francisco Javier Cevallos Candau, Jeffrey A. Cole, Nina M. Scott, y Nicomedes Suárez Araúz, eds. Amherst: University of Massachusetts Press, 1994. 255-62.

“¿Cómo narrar la nación? El Círculo de Domingo Del Monte y el surgimiento de la novela cubana”. Cuadernos Americanos 45 (mayo-junio 1994): 103-25. La isla que se repite. Hanover: Ediciones del Norte, 1996.

Bhabha, Homi. Nation and Narration. Nueva York: Routledge, 1991.

González Echevarría, Roberto. Myth and Archive. A Theory of Latin American Narrative. Cambridge: Cambridge University Press, 1990.

Guízar Álvarez, Eduardo y Adriana Méndez Rodenas. “Caña/cuerpo/danza: Imágenes de opresión/liberación del sujeto caribeño”. Crítica Hispánica 22/1 (2000): 61-77.

Hoffman, E. T. A. Tales of Hoffmann. Christopher Lazare, ed. Nueva York: A. A. Wyn, 1946.

Jensen, Larry R. Children of Colonial Despotism. Press, Politics, and Culture in Cuba 1790-1840. Tampa: University of South Florida Press, 1988. 
Luis, William. Literary Bondage. Slavery in Cuban Narrative. Austin: The University of Texas Press, 1990.

Martí, José. Nuestra América. Hugo Achúgar, ed. Caracas: Biblioteca Ayacucho, 1977. Méndez Rodenas, Adriana. Gender and Nationalism in Colonial Cuba. The Travels of Santa Cruz y Montalvo Condesa de Merlín. Nashville: Vanderbilt University Press, 1998.

Mera, Juan León. Cumandá, o, un drama entre salvajes. Quito: J. Guzmán Almeida, 1879. Moliner, María. Diccionario de uso del español. 2 tomos. Madrid: Gredos, 1966-67.

Moreno Fraginals, Manuel. El ingenio. Complejo económico social cubano del azúcar. Vol. 1. La Habana: Editorial de Ciencias Sociales, 1978.

Sommer, Doris. Foundational Fictions. The National Romances of Latin America. Berkeley: University of California Press, 1993.

Villaverde, Cirilo. Cecilia Valdés. Ed. Raimundo Lazo. México: Editorial Porrúa, 1972. Excursión a Vueltabajo. Habana: Biblioteca Habanera, 1891. 